\title{
KAJIAN PERANCANGAN RUANG KOMUNITAS SENI SKETSA PERJALANAN JAKARTA
}

\author{
Andrew Christian ${ }^{1)}$, Sutarki Sutisna ${ }^{2)}$ \\ 1)Program Studi S1 Arsitektur, Fakultas Teknik, Universitas Tarumanagara, andrewchristian93@gmail.com \\ 2) Program Studi S1 Arsitektur, Fakultas Teknik, Universitas Tarumanagara, sutarkis@gmail.com
}

\begin{abstract}
Abstrak
Generasi Milenial terutama di Ibu Kota Jakarta cerita pengalaman dan perjalanan di suatu tempat tidak akan lupa momen tersebut untuk diabadikan, menjadi sebuah gaya hidup milenial, hingga tanpa disadari momen yang diabdikan tersebut hanya untuk kesenangan dan keegoisan diri sendiri, hingga melupakan karakteristik dan kebudayaan yang ada di tempat yang sedang dikunjungi. Indonesia merupakan salah satu negara yang memiliki pertumbuhan parwisata yang sedang tinggi saat ini dengan karakteristik, kebudayaan dan kekayaan alam yang ada. Sehingga pemerintah meningkatkan perekonomian dari sektor pariwisata. Salah satu contohnya Ibu Kota Jakarta, kota Jakarta selain menjadi pusat adminstratif negara, juga memiliki sejarah dan latar belakang yang sangat kuat, namun seringkali hal tersebut di lupakan. Komunitas Travelsketch merupakan sebuah komunitas seni sketsa yang mendokumentasi suatu kejadian dengan menggunakan sketsa. Kegiatan dokumentasi komunitas ini bertujuan untuk mempelajari dan mengamati kebudayaan yang ada dan untuk berekspresi. Tujuan dari rancangan ini adalah untuk membentuk pola ruang interaksi yang sesuai dengan karakter travelsketch dan milenial dan bagaimana generasi milenial dapat tertarik untuk mengenal kebudayaan dan karakter suatu tempat. Dalam proses perancangan pola ruang karakteristik travelsketch dan pola kawasan di Kota Tua menjadi dasar membentuk sebuah konsep ruang, sehingga rancangan yang di bangun selaras dengan kawasan Kota Tua. Komunitas Seni Sketsa Perjalanan Jakarta ini di rancang untuk memperkenalkan kebudayaan dan karakter suatu tempat melalui sebuah seni sketsa, sehingga komunitas ini dapat menjadi sebuah wadah pertunjukan dan edukasi yang membagikan pengalaman ketika berada di suatu tempat. Melaui rancangan ini pengenalan karakteristik dan pengunjung wisata yang ada di suatu tempat dapat meningkat.
\end{abstract}

Kata kunci: Karakteristik; Kebudayaan; Komunitas; Milenial; Sketsa

\begin{abstract}
Milenials, especially in the capital city of Jakarta, stories of experience and travel in one place will not forget that moment to be immortalized, become a milenial lifestyle, until unwittingly the devoted moment is only for pleasure and selfishness, to forget the existing characteristics and culture in the place that is being visited. Indonesia is one of the countries that has a growing tourism sector that is currently high with the characteristics, culture and natural resources that exist. So that the government increases the economy from the tourism sector. One example is the capital city of Jakarta, the city of Jakarta in addition to being the administrative center of the country, it also has a very strong history and background, but often it is forgotten. Travelsketch community is a sketch art community that documents an event using sketches. This community documentation activity aims to study and observe existing cultures and expressions. The purpose of this design is to form patterns of interaction space that are in accordance with the character of travelsketch and milenials and how the milenial generation can be interested in getting to know the culture and character of a place. In the process of designing the pattern of space characteristics of travelsketch and regional patterns in Kota Tua, Jakarta become the basis for forming a concept of space, so that the design is built in harmony with Kota Tua area. The Jakarta Travel Sketch Art Community is designed to introduce culture and character to a place through a sketch art, so that this community can become a venue for performances and education that shares experiences when in a place. Through this design the introduction of characteristics and tourist visitors that exist in a place can increase.
\end{abstract}

Keywords: Characteristics; Community; Culture; Millenial; Sketch 


\section{PENDAHULUAN}

\section{Latar Belakang}

Indonesia merupakan salah satu negara dengan pertumbuhan pariwisata tertinggi peringkat ke-9 di dunia berdasarkan The World Travel \& Tourism Council (WTTC), hal tersebut di dukung dengan meningkatkan pariwisata dari sektor nasional maupun mancanegara dari tahun 2015 - 2017.

Salah satu karakter generasi Milenial yaitu travelling (jalan-jalan). Karakter ini merupakan salah satu faktor meningkatnya pertumbuhan pariwisata di Indonesia. Travelling menjadi sebuah hoby bagi generasi milenial karena generasi ini suka untuk mencari hal-hal baru yang menarik. Teknologi membuat pengenalan akan suatu daerah wisata lebih mudah di kenal berdasarkan cerita, foto maupun gambar suatu tempat. Foto dan gambar merupakan kegiatan mendokumentasi dan membuat cerita apa yang milenial alami di suatu tempat.

Kementrian Pariwisata bekerjasama dengan Badan Ekonomi Kreatif Indonesia (Bekraf) untuk meningkatkan perekonomian negara Indonesia melalui industri kreatif. Seni Rupa merupakan salah satu sektor yang kurang berkembang di antara sektor lainya karena adanya masalah pemasaran dalam negeri dan faktor edukasi dari para ahli dalam bidang seni rupa sendiri.

Menanggapi permasalahan tersebut muncul komunitas-komunitas sketsa yang ada di Indonesia sejak tahun 2009 (Indonesia's Sketchers), yang merupakan generasi yang suka travelling dan mendokumentasi suatu tempat dengan menggunakan sketsa atau gambar dengan tangan secara langsung. Urban Sketchers Singapore merupakan komunitas sketsa yang ada di Singapur dan merupakan komunitas yang terdiri dari generasi sama dengan yang ada di Indonesia. Travelsketch menjadi sebuah sarana edukasi kreatif bagi generasi milenial dan non milenial yang memiliki karakter untuk berpergian dengan mengenal budaya dan karakter wisata dari suatu tempat yang berkaitan dengan perkembangan pariwisata di Indonesia.

Untuk ini perlu wadah bagi para generasi milenial dan non milenial ini untuk mengekspresikan karya seninya dan memperkenalkan kebudayaan dan karakteristik suatu tempat dengan menggunakan sketsa, sehingga pariwisata di suatu tempat dapat lebih dikenal dan menjadi aspek sketsa aspek penunjang seni rupa di Indonesia.

\section{KAJIAN LITERATUR}

\section{Badan Ekonomi Kreatif}

Badan Ekonomi Kreatif Indonesia bekerja sama dengan kementrian pariwisata Indonesia dalam memajukan perekonomian negara. Perkembangan dan pengenalan karakter pariwisata di Indonesia dapat ditingkatkan melalui industri kreatif, namun dari 16 subsketor target pelaksanaan ekonomi Kreatif di Indonesia, masih terdapat beberapa subsektor yang masih belum terlihat dan berkembang di Indonesia.

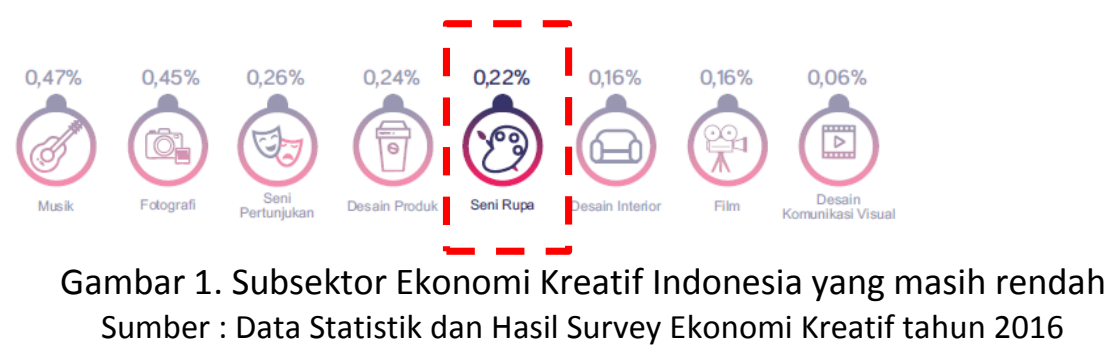

Seni Rupa merupakan sebuah subsektor yang kurang berkembang di bandingkan subsektor kuliner, dan fashion karena seperti kendala yang dialami terkait dengan pemasaran di dalam negri dan edukasi akan Seni itu sendiri. Generasi Milenial memiliki karakter travelling dan suka mendokumentasi cerita yang mereka alami di suatu tempat dengan foto atau dengan menggambar. Fenomena yang terjadi generasi milenial hanya sekedar memfoto tempat tersebut tanpa mengetahui budaya dan karakteristik yang ada di tempat tersebut. Sehingga 
perlu adanya wadah edukasi kreatif dari sektor seni rupa yang dapat jawab karakter travelling dan menjadi wadah ekspresi seniman yang ada. Hal ini dapat menjadi sebuah potensi untuk pertumbuhan dan perkembangan sebuah daerah wisata.

\section{Travelsketch}

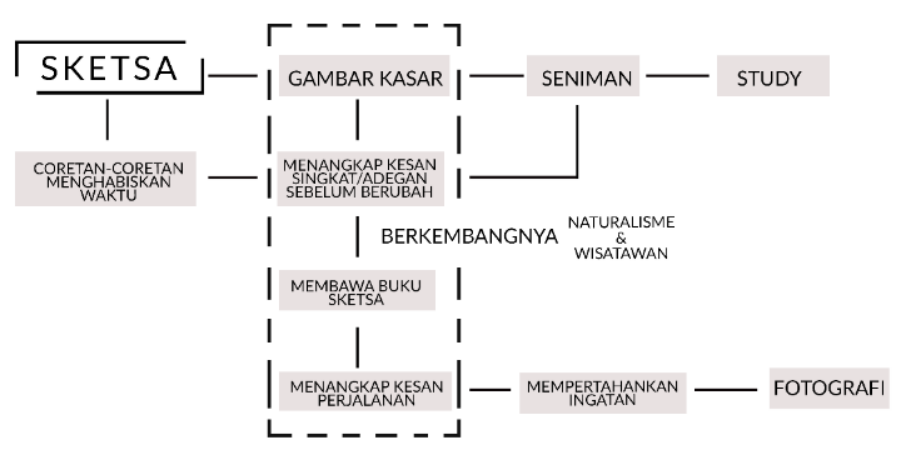

Diagram 2. Diagram rangkuman studi sketsa.

Sumber : http://www.visual-arts-cork.com/sketching.htm

Salah satu bagian dari seni adalah seni rupa menggambar atau sketsa. Sketch / Sketsa adalah gambar yang kasar dan ringan, atau gambaran garis besarnya dari suatu gambar atau lukisan. Sketsa secara tradisional mengacu pada jenis gambar kasar awal yang mungkin dibuat oleh seorang seniman sebagai persiapan untuk lukisan atau gambar yang lebih formal/lukisan (seperti studi). Berikut merupakan perbandingan antara foto dan gambar secara umum dan bagimana peranan dari foto maupun gambar yang menjadi cara untuk mendokumentasikan kejadian di suatu tempat.

\section{Community Area}

Definisi dari Community Area berdasarkan arti kata adalah "a building or group of buildings for a community's educational and recreational activities", sebuah bangunan atau sebuah kumpulan bangunan untuk edukasi suatu komunitas dan memberikan aktifitas rekreasi. Terdapat aktifitas dan fungsi yang terjadi di ruang komunitas antara lain :

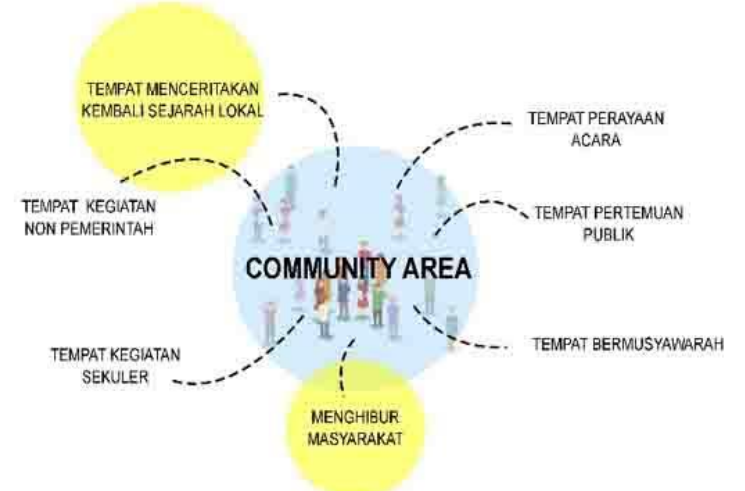

Gambar 3. Diagram Aktifitas dan Fungsi Community Area Sumber : https://www.merriam-webster.com/dictionary/community\%20center

Berdasarkan diagram, community area dapat menjadi sebagai tempat untuk menceritakan kembali sejarah lokal yang ada di suatu tempat dan menjadi tempat untuk menghibur masyarakat yang ada. Sehingga kedua fungsi tersebut menjadi batasan fungsi yang akan di angkat terkait dengan travelsketch dan pariwisata yaitu Exploration, Education, Exploration dan Entertainment. 


\section{Program Ruang}

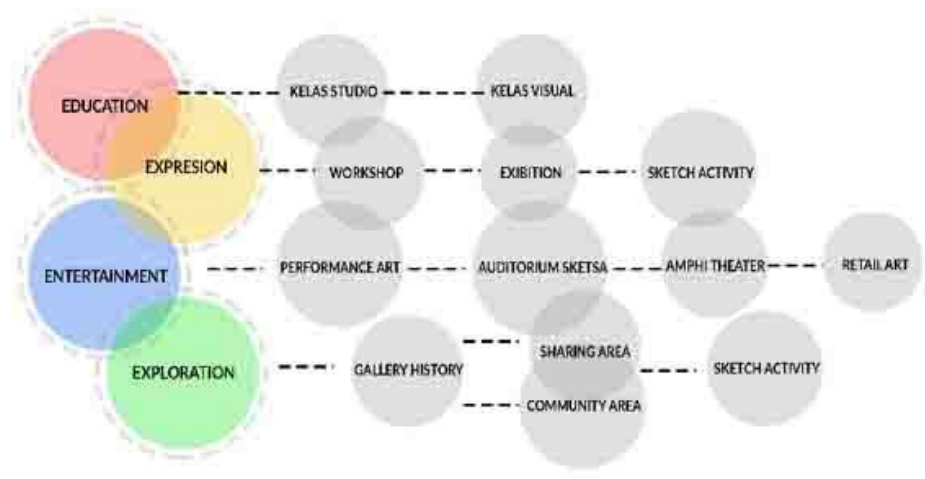

Gambar 4. Program Utama Bangunan

Sumber: Penulis, 2019

\section{Education}

Edukasi merupakan ruang pelatihan atau kelas-kelas dari performance art yang di tampilkan dan seni sketsa yang di pamerkan. Ruang kelas yang di bentuk dapat bersifat outdoor dan indoor. Ruang kelas bersifat studio dan studio visual.

\section{Expresion}

Ruang ini merupakan ruang sketchers untuk berekspresi berupa ruang aktivitas sketsa. Ruang yang ada diantaranya ruang Workshop, Exibition, dan Sketch Activity. Ruang Workshop yang ada bersifat terbuka dan tertutup, sehingga para sketchers dapat membagikan ilmu dan pengalaman secara langsung saat melakukan sketsa.

\section{Entertaiment}

Entertaiment merupakan sebuah ruang yang ditujukan untuk pengunjung untuk menyaksikan komunitas sketsa saat melakukan kegiatan menggambar dengan menggunakan berbagai media. Ruang yang tebentuk yaitu Performance area, Auditorium Area, Amphitheater dan Retail art.

\section{Exploration}

Exploration merupakan program agar pengunjung dapat mengetahui dan mempelajari sejarah yang ada di kota tua, dan sejarah perkembagan dari seni rupa sketsa. Sehingga ruang yang terbentuk dari program exploration tersebut yaitu berupa history Kota Tua, history sketch, sharing area, community area, dan sketch activity.

\section{METODE}

\section{Data Penelitian}

Data yang digunakan sebagai sumber penyusunan perancangan proyek arsitektur ini adaalah sebagai berikut :

- Hasil survey kusioner generasi milenial terhadap travelsketch

- Hasil survey lapangan mengenai tapak dan lingkungan sekitar

- Hasil perbandingan antara sketsa dengan foto

- Studi perbandingan beberapa bangunan sejenis.

\section{Metode Pengumpulan Data}

Metode penulisan dengan menggunakan literatur-literatur, hasil survey melalui kuisioner, foto dan sketsa lapangan. Literatur-literatur digunakan untuk memperdalam isu dan kebutuhan generasi milenial dan untu perbandingan dengan data kusisioner dan lapangan. Kuisioner di berikan kepada 75 responden yang terdiri dari mahasiswa, karyawan, dan seniman 
untuk memperoleh tanggapan generasi milenial terhadap travelsketch yang akan di tuangkan kedalam rancangan berupa pola karakteristik ruang.

\section{DISKUSI DAN HASIL}

\section{Analisa Tapak}

Makro, Jakarta Barat

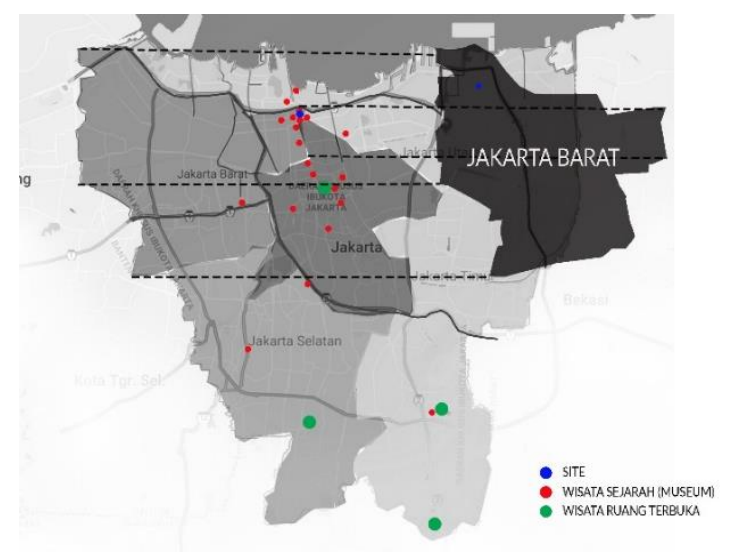

Gambar 5. Peta Kota Jakarta

Sumber :googlemaps/jakarta.com

Berdasarkan diagram diatas kota Jakarta merupakan kota yang memiliki destinasi wisata sejarah yang tinggi ditandai dengan adanya museum-museum peninggalan-peninggalam sejarah di Indonesia. Jakarta Barat menjadi salah satu pusat wisata bersejarah di kota Jakarta. Wisata museum di Jakarta Barat berjumlah kurang lebih 12 tempat wisata berada diatas wilayah kota Jakarta lainnya, sehingga kawasan dapat menjadi potensi pengikat wisatawan lokal maupun internasional.

\section{Meso, Jakarta Barat sebagai Kawasan Kota Tua}

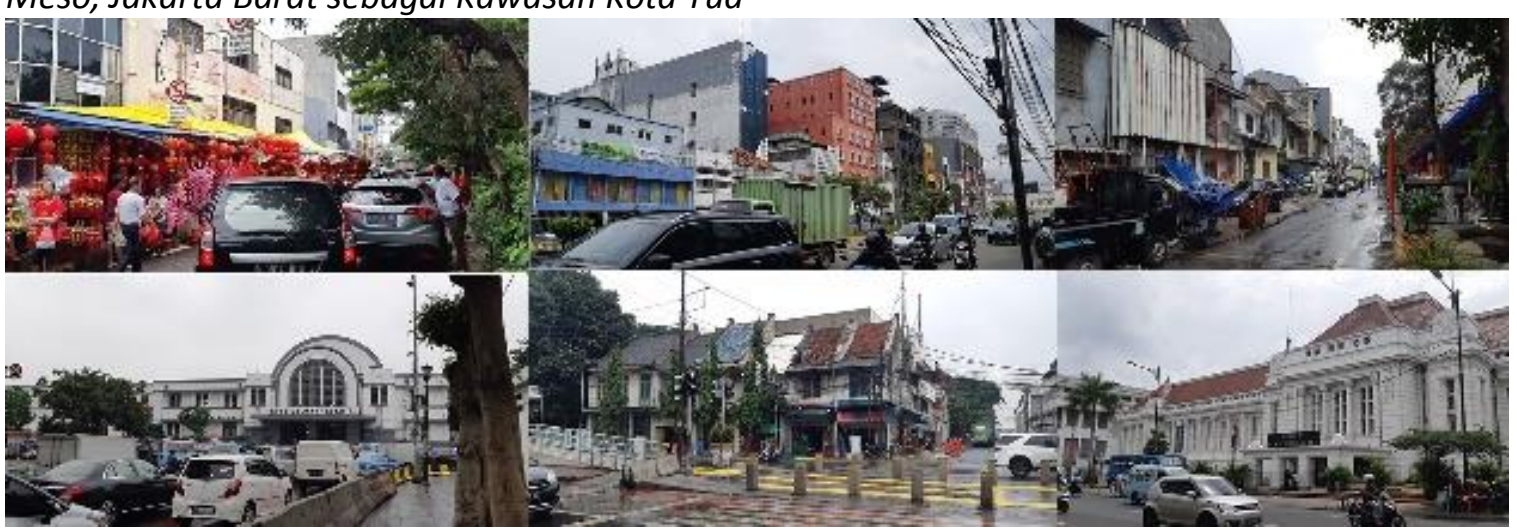

Gambar 6. Program Utama Bangunan Sumber: Penulis, 2019

Kondisi eksisting yang ada di sekitar kawasan terdapat bangunan-bangunan peninggalan zaman penjajahan Belanda yang masih ada. Daerah di sekitar kawasan mamiliki 2 karakteristik kawasan yaitu kawasan Kota Tua dengan karakteristik kolonial dan kawasan Pecinan Glodok dengan karakteristik kebudayaan Tiong Hoa, sehingga rancangan nantinya akan menerapkan karakteristik yang ada di kawasan ke dalam bangunan dan bentuk massa rancangan. 


\section{Tata Guna Lahan dan Ruang Terbuka}
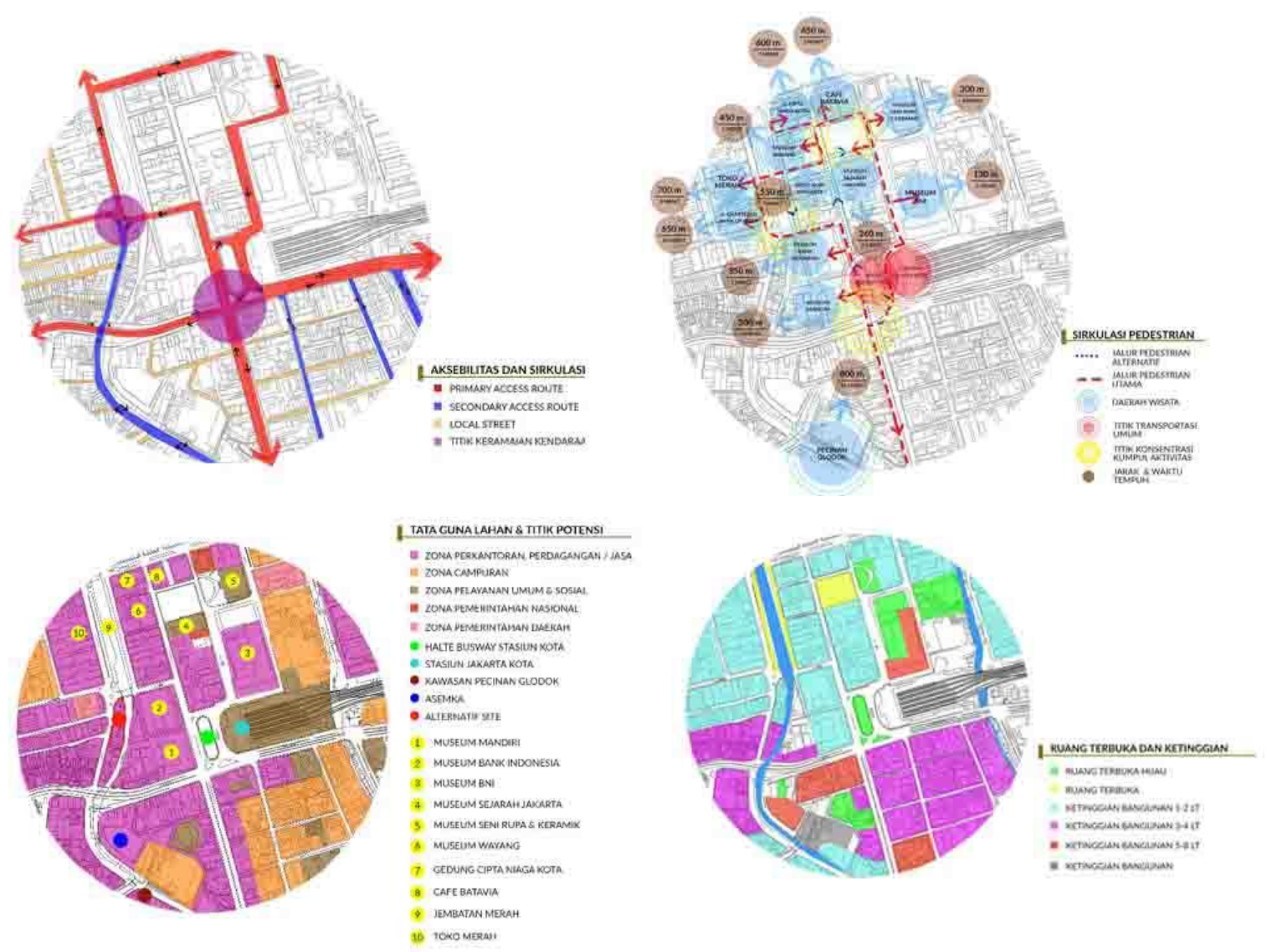

Gambar 7. Diagram Tata Guna Lahan dan Ruang Terbuka Sumber: Penulis, 2019

Tata guna lahan yang ada di kawasn antara lain adalah Zona perkantoran, perdagangan dan jasa, zona campuran, dan zona pelayanan umum. Selain itu tapak berada dekat dengan beberapa titik wisata yang ada di kawasan Kota Tua dengan ketinggian bangunan yang ada di sekitar area kawasan bervariasi dari rendah hingga tinggi. Ruang terbuka yang ada di sekitar kawasan merupakan ruang terbuka publik space dan masih kurang adanya ruang terbuka hijau di kawasan.

\section{Aksebilitas Kendaraan dan Sirkulasi Pedestrian}

Mapping kawasan diatas merupakan mapping untuk melihat kemungkinan jalur sirkulasi yang kendaraan pedestrian lakukan dari titik jalan utama Jalan Pintu Besar Selatan dan moda trasportasi umum yang ada. Sehingga akan terlihat tapak berada di kawasan yang aktif karena berada dekat dengan lingkungan perdagangan mangga dua dan perumahan di angke dan jangkauan dan waktu tempuh yang dibutuhkan seseorang ketika berjalan kaki disekitar tapak. Kawasan Kota tua menjadi penghubung dua kegiatan perdagangan dan pemukiman dan dari mapping pedestrian bertujuan untuk melihat waktu yang di butuhkan oleh sketchers ketika berjalan dan mengamati daerah wisata di sekitar kawasan memerlukan berapa waktu tempuh dan jaraknya. 


\section{Mikro, Tapak}
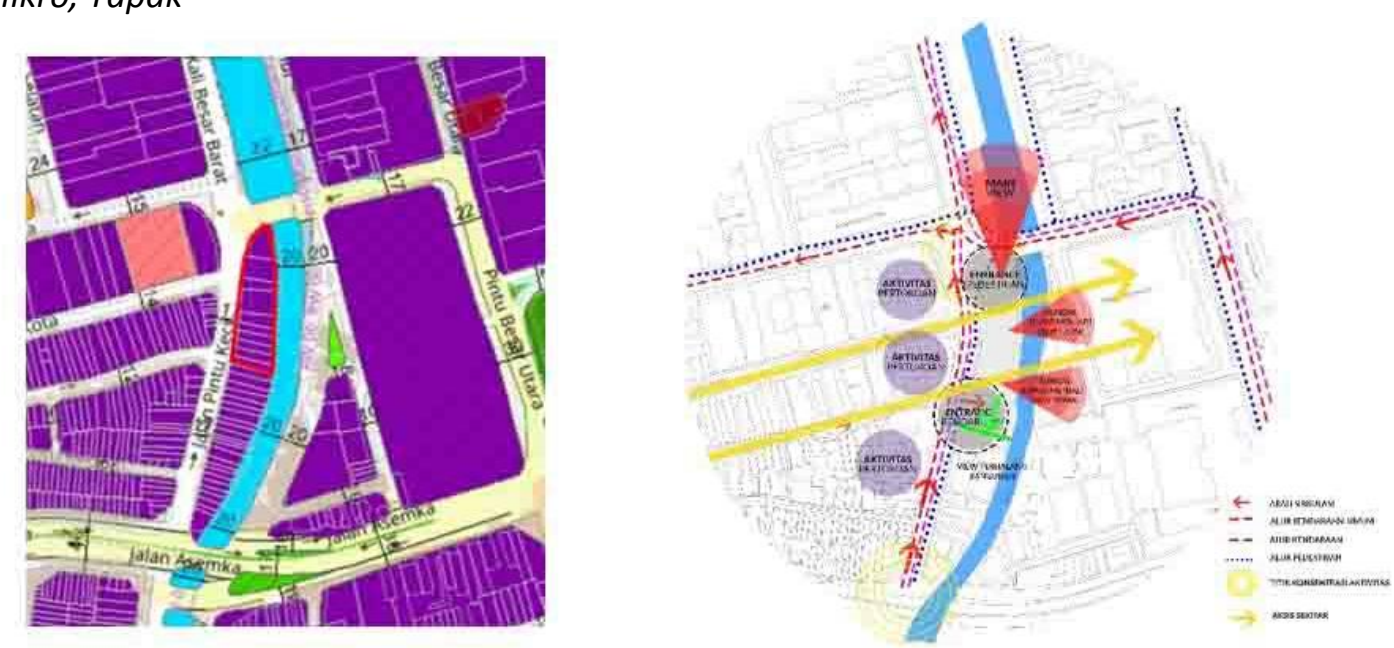

Gambar 8. Peta Zonasi Tapak dan Diagram Analisa Tapak Sumber: Penulis, 2019

Kondisi yang terlihat di area sekitar tapak yaitu daerah pertokoan, perdagangan dan jasa. Di sebelah utara tapak berbatasan dengan wisata Waterwalk Kanal Kota Tua, sebelah timur Museum Bank Indonesia dan sebelah barat dan selatan merupakan perkantoran, pertokoan dan jasa. Sirkulasi yang melintas di area sekitar tapak yaitu dari arah Jl. Pintu Kecil dan Jl. Pintu Besar Utara yang mengarah ke Jl. Malaka dan JI.Kali Besar Barat. Berdasarkan diagram di atas sirkulasi kendaraan yang melintasi tapak hanya satu arah saja sehingga pencapain hanya dapat melalui Jl. Pintu Besar Utara dan JI. Pintu Kecil. Sehingga pintu masuk atau entrance menuju tapak berada di bagian selatan tapak untuk sirkulasi kendaraan dari arah Asemka menuju Kota Tua melalui Jl, Pintu Kecil.

Kondisi eksisting yang ada di sekitar tapak membentuk sebuah view dan vista dari arah tapak. View utama dari tapak yaitu mengarah ke wisata Waterwalk Kanal Kota Tua dan view mengarah ke arah timur tapak menuju Kali Besar dan Museum Bank Indonesia. Selain kedua tempat wisata tersebut yang nantinya akan menjadi salah satu objek dari para sketchers saat menggambar, terdapat aktivitas-aktivitas yang ada di sekitar tapak yang nantinya akan menjadi objek gambar dari para sketchers sehingga kehidupan yang ada di sekitar tapak dapat di bawa kedalam bangunan.

Konsep

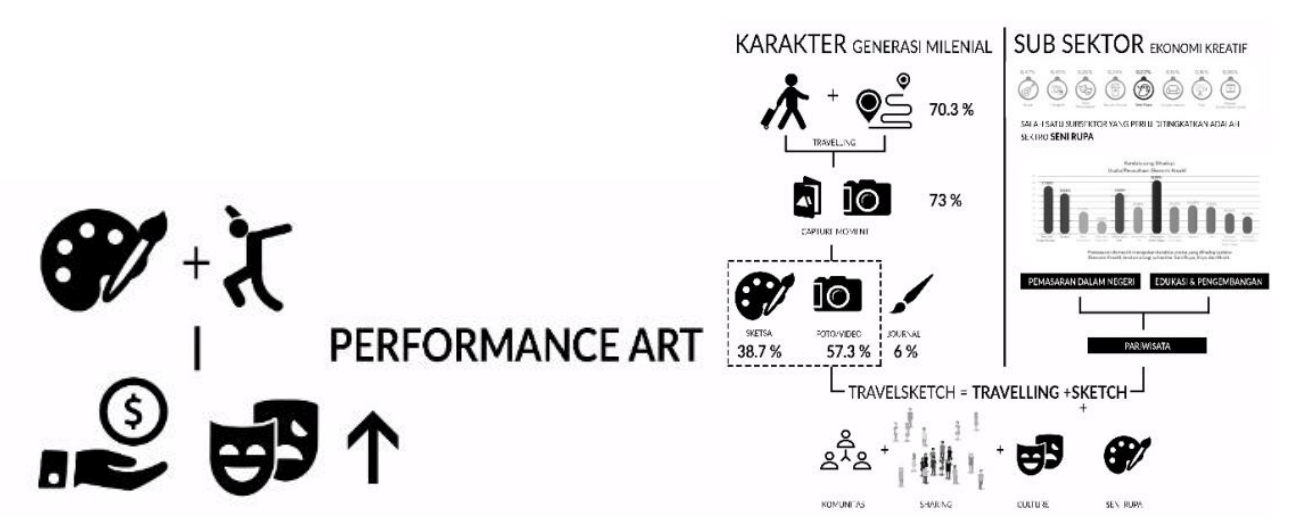

Gambar 9. Diagram Konsep dan Konsep Performance Art

Sumber: Penulis, 2019

Travelsketch merupakan sebuah konsep yang berangkat dari isu yang terjadi di generasi milenial. Milenial yang suka untuk travelling dan suka untuk mengcapture suatu kejadian 
dengan menggukan kamera dan sketsa dilakukan secara bersamaan untuk mendokumentasi suatu kejadian. Hal ini dapat berpengaruh dan meningkatkan program yang di berikan pemerintah yang saat ini mengalami kendala yaitu terkait pemasaran dalam negeri. Performance art menjadi sebuah konsep yang di angkat, yaitu sebuah konsep yang menjadikan kegiatan komunitas seni sketsa yang ada di Jakarta menjadi sebuah tontonan bagi pengunjung wisata Kota tua. Oleh sebab itu konsep Travelsketch diharapkan dapat meningkatkan pengenalan wisata yang ada di Kota Tua melaui aktivitas membuat Karya Seni.

Konsep kemudian berangkat dari karakteristik dan kebutuhan dari Sketchers yang ada di Jakarta dan Pola bentuk kawasan yang ada hingga membentuk sebuah gambaran pola sifat ruang yang akan di terapkan ke dalam desain.

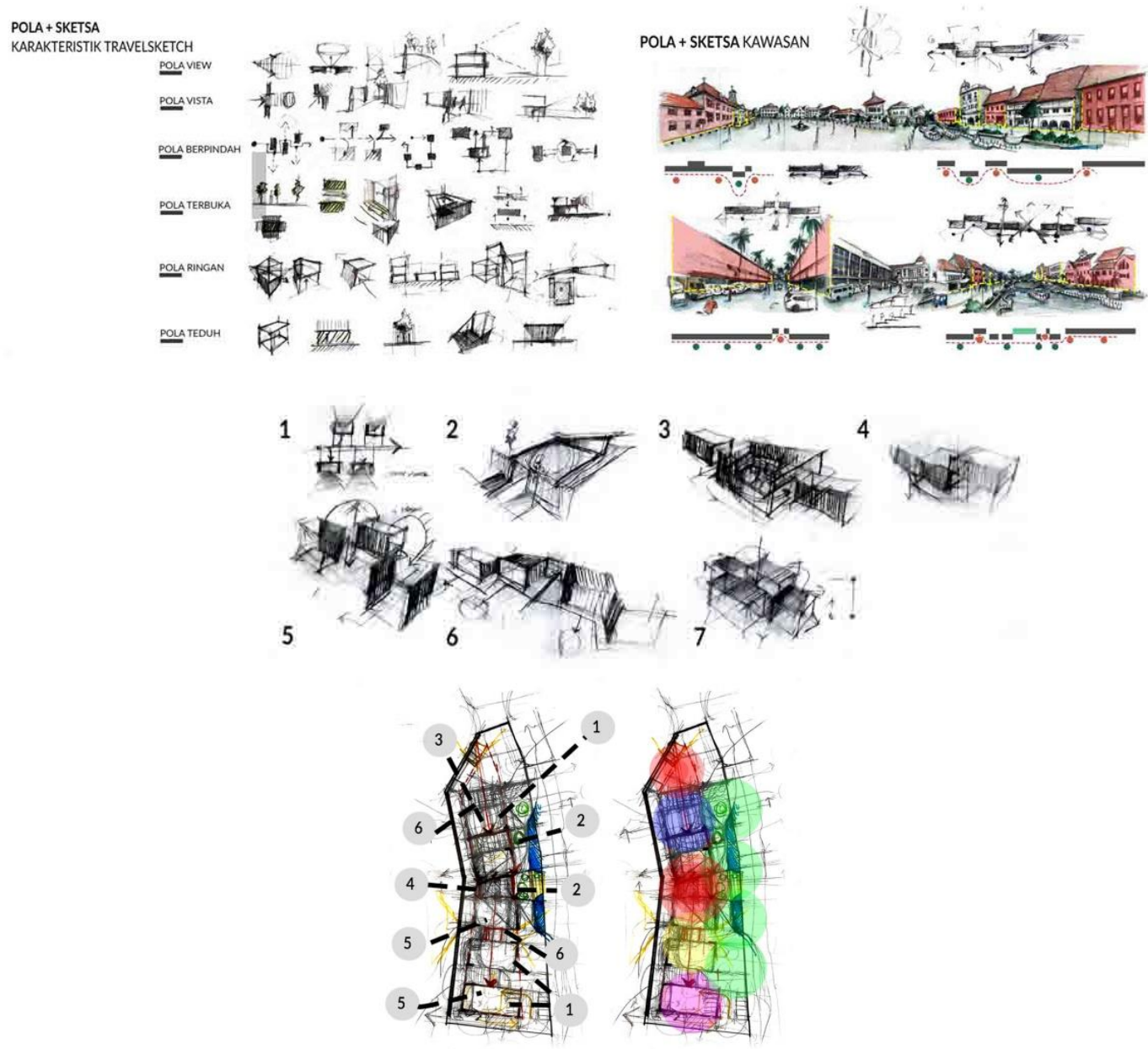

Gambar 10. Diagram Pola dan Sketsa Karakteristik Travelsketch dan Kawasan Kota Tua Sumber: Penulis, 2019

Dari gambaran pola karakter dan kawasan yang sudah di buat membentuk pola karakter yang ada seperti adanya pembatas ruang, permainan ketinggian bangunan, sirkulasi yang terbentuk dari pola berpindah-pindah, struktur bangunan yang digunakan, dan penempatan vegetasi. Dan pola kawasan yang terbentuk terdapat massa bangunan yang maju mundur, sehingga membentuk ruang ruang terbuka dan void di kawasan serta membentuk pola sirkulasi. 
Pola Sifat ruang yang terbentuk kemudian di terapkan kedalam design di terapkan kedalam blok plan dan di buat skematik zoning program dan membentuk gubahan massa bangunan sesuai dengan pola yang ada.

Bagian depan massa bangunan yang mengarah ke jalan utama menjadi zona publik untuk menangkap pedestrian dari wisata Waterwalk Kanal Kota Tua dan massa di bagian balakang tapak menjadi zona administratif dan private untuk kelas-kelas studio dan workshop. Courtyard atau amphitheater menjadi pengikat antar kedua bagian tersebut dengan adanya performance art dari seniman sketsa Jakarta. Kemudian Bentuk Atap massa berbentuk pelana mengikuti bentuk bangunan yang ada di sekitar kawasan Kota Tua, dan bagian atap di beri skylight untuk pencahayaan dan sirkulasi udara.

Tepat berada di samping Kali Besar dibuat landscape yang menjadi public area dan dapat menjadi sharing area dan kegiatan komunitas-komunitas sketsa dengan adanya pohon yang memberi penefuhan. Pada gambar kedua merupakan gambaran ruang studio sketsa dan ruang workshop yangmendapat pencahayaan dari skylight dari atap bangunan, hal ini di lakukan untuk membuka imajinasi dan ekspresi pengunjung yang ingin belajar.

\section{KESIMPULAN DAN SARAN}

Komunitas Seni Sketsa Perjalanan Jakarta merupakan sebuah ruang ekspresi, ruang komunitas sekaligus ruang edukasi seni bagi generasi milenial yang senang traveling dan mendokumentasi cerita yang mereka alami saat berada di kawasan Kota Tua. Ruang komunitas ini menjadi media pengenalan karakteristik dan kebudayaan di kawasan Kota Tua melalui media seni sketsa, dengan melihat dan menyaksikan performance seniman-seniman yang melakukan kegiatan menggambar. Hal ini untuk menarik minat wisatawan dan generasi milenial terhadap seni sketsa perjalanan dan pengenalan akan karakteristik suatu daerah wisata, sehingga wisata kawasan Kota Tua dapat semakin dikenal dan berkembang. Pendekatan metode perancangan yang digunakan dengan melihat pola dan karakter kawasan dan sketchers sehingga rancangan senada dengan kawasan di kota Tua. Melalui perancangan ruang Komunitas Seni Sketsa Perjalanan Jakarta ini dapat mewadahi seniman travelsketch yang ada di Indonesia dan meningkatkan pariwisata dan karakteristik kawasan Kota Tua.

\section{REFERENSI}

Anderson, L. (2018). 4 Insights on Milenial Travel Behavior, diunduh 3 Februari 2019, dari https://www.lsb.com/blog/4-insights-on-milenial-travel-behavior/

Badan Pusat Statistik. (2019). Persentase Penduduk Daerah Perkotaan menurut Provinsi, 20102035. Diunduh 15 Januari 2019, dari https://www.bps.go.id/statictable/2014/02/18/1276/persentase-penduduk-daerahperkotaan-menurut-provinsi-2010-2035.html

Dini, M. (2017). Jenis - Jenis Tempat Wisata Berdasarkan Motif Wisatawan, Lokasi Tujuan dan Perjalanan. Diakses 20 Februari 2019, di https://tempatwisataunik.com/info-wisata/jenisjenis-tempat-wisata

Dwiputri, P. (2018). Facilitating the Creative Process. Diakses 30 Maret 2019, di https://www.whiteboardjournal.com/focus/living/anjung-salihara/

Ekarina. (2019). Incar 20 Juta Wisman di 2019, Kemenpar, Kembangkan Wisata Perbatasan. Diunduh 12 Januari 2019, dari https://katadata.co.id/berita/2019/01/11/incar-20-jutawisman-di-2019-kemenpar-kembangkan-wisata-perbatasan

Ibo, A. (2017). Urban sketch Makin Hits di Kalalangan Milenial. Diunduh 4 Februari 2019, dari https://www.liputan6.com/lifestyle/read/3150505/urban-sketch-makin-hits-di-kalanganmilenial

Nadia, C. (2018). Data Statistik dan Hasil Survey Khusus Ekonomi Kreatif. Diunduh 20 Februari 2019, dari http://www.bekraf.go.id/pustaka/page/data-statistik-dan-hasil-survei-khususekonomi-kreatif 
Panorama Group. (2014). Panorama Gelar "101 Travel Sketch Edisi Jakarta". Diakses 24 Februari 2019, di http://www.panorama-group.com/pg/news/detail/147

Pitra, H. (2016). Performance Art Dalam Arsip: (Isu) Apa, (Oleh) Dan (Untuk) Siapa?. Diakses 5 Maret 2019, di http://ivaa-online.org/2016/02/13/performance-art-dalam-arsip-isu-apaoleh-dan-untuk-siapa/

Thamrin, M. (2018). Cerita Avianti Armand Tentang Pameran Impromptu Muhammad Thamrin. Diunduh 11 Februari 2019, dari http://sketchwalker.com/index.php/cerita-aviantiarmand-tentang-pameran-impromptu-muhammad-thamrin/

Wijanarko, T. (2018). Pertumbuhan Pariwisata Indonesia Peringkat 9 di Dunia. Diunduh 2 Januari 2019, dari https://travel.tempo.co/read/1139099/pertumbuhan-pariwisataindonesia-peringkat-9-di-dunia 